\title{
Short communication: Evaluation of confirmatory stains used for direct microscopic somatic cell counting of sheep milk
}

\author{
K. H. Petersson, ${ }^{\star 1}$ L. A. Connor, ${ }^{\star}$ C. S. Petersson-Wolfe, $†$ and K. A. Rego* \\ *Department of Fisheries, Animal and Veterinary Science, University of Rhode Island, Kingston 02881 \\ †Department of Dairy Science, Virginia Tech University, Blacksburg 24061
}

\begin{abstract}
Current FDA regulatory screening and confirmatory methods, electronic cell counting and the direct microscopic somatic cell count (DMSCC), differ for the detection of abnormal milk in sheep and goats. The DNA-specific electronic SCC screening methods such as Fossomatic (Foss, Hillerød, Denmark) can be used for both sheep and goat milk; however, the nonspecific methylene blue-based stains used for DMSCC in sheep cannot be used for goats as they nonspecifically stain cytoplasmic particles naturally present in goat milk. The DNA-specific stain pyronin Y-methyl green (PMG) is currently used for DMSCC in goats. Sheep also shed cytoplasmic particles during the milk secretory process, but in fewer numbers than goats. The objective of this study was to determine whether the nonspecific, methylene blue-based Levowitz-Weber (L-W) stain is the appropriate regulatory stain to use for DMSCC in sheep milk. Composite milk samples from 42 commercial dairy ewes were collected every $4 \mathrm{wk}$ for the duration of each ewe's lactation for a total of 10 sample days. Milk samples were subjected to 3 methods of SCC determination: automated Fossomatic counting, DMSCC with L-W stain, and DMSCC with PMG stain conducted according to FDA regulatory procedures (2400 series forms). The DMSCC from milk smears stained with L-W were greater than those from smears stained with PMG and those from the Fossomatic analysis on 6 of the 10 sampling days. Milk smears stained with PMG did not differ from Fossomatic analysis at any sampling. The average milk SCC for L-W, PMG, and Fossomatic were $($ mean $\pm \mathrm{SE}) 275 \pm 36 \times 10^{3}, 174 \pm 24 \times 10^{3}$, and $164 \pm 24 \times 10^{3}$ cells $/ \mathrm{mL}$, respectively. The DMSCC for milk stained with L-W was $58 \%$ greater than that with PMG and $68 \%$ greater than that obtained with the Fossomatic analysis. In conclusion, DMSCC of sheep milk stained with the nonspecific, methylene blue L-W stain resulted in a marked increase in SCC over that of the
\end{abstract}

Received June 28, 2010.

Accepted November 23, 2010.

${ }^{1}$ Corresponding author: kpetersson@uri.edu
DNA-specific stain PMG and Fossomatic SCC analysis. The findings of this study support the continued use of Fossomatic SCC but recommend the replacement of the methylene blue-based stains with DNA-specific PMG for determination of DMSCC in sheep milk.

Key words: direct microscopic somatic cell count, Levowitz-Weber stain, pyronin Y-methyl green stain, sheep

\section{Short Communication}

The current FDA regulatory screening and confirmatory methods, DNA-specific fluoro-optical electronic cell counting (Fossomatic; Foss, Hillerød, Denmark) and direct microscopic somatic cell count (DMSCC), differ in the detection of abnormal milk in sheep and goats (Fitts and Laird, 2004; PMO, 2007). A nonspecific methylene blue-based stain such as LevowitzWeber $(\mathbf{L}-\mathbf{W})$ is used for the DMSCC in sheep and the DNA-specific pyronin Y-methyl green (PMG) is used for DMSCC in goats. Previously, L-W was used for DMSCC in goat milk (Marth, 1978); however, Dulin et al. (1982) demonstrated that the L-W stain was unsuitable as a confirmatory somatic cell stain in goat milk because of the nonspecific staining of the cytoplasmic particles found in goat milk (Dulin et al., 1983; Droke et al., 1993; Sanchez et al., 2005).

The glandular secretion of milk by the ewe is characterized by the release of cytoplasmic particles and cell fragments during the milk excretion process (Gonzalo et al., 2003), albeit in far fewer numbers than in goats (Martinez et al., 1997). Similar to its use in goats, the use of methylene blue-based stains for sheep milk may artificially elevate the SCC due to the nonspecific staining of the cytoplasmic fragments that are present in the milk. These stains, therefore, may not be appropriate regulatory stains to use for the determination of DMSCC in sheep. To change a standard in the grade "A" Pasteurized Milk Ordinance (PMO, 2007), a study has to be conducted that follows regulatory procedures. To the best of our knowledge, no such study has been conducted with sheep, as was conducted for goats (Dulin et al., 1982), to compare the L-W DMSCC stain 
with the PMG stain or Fossomatic analysis following FDA regulatory procedures (Fitts and Laird, 2004). The objective of this study was to determine whether the nonspecific, methylene blue-based $\mathrm{L}-\mathrm{W}$ stain is the appropriate regulatory stain to use for DMSCC in sheep milk. This study compared DMSCC for sheep milk, sampled across an entire lactation and conducted according to FDA regulatory procedures, using the nonspecific L-W stain, with the DNA-specific PMG stain and Fossomatic analysis of SCC (FOSS).

Milk samples from 42 commercial, East Friesian purebred and crossbred dairy ewes (Old Chatham Sheepherding Company, Old Chatham, NY) were used in this study. Criteria for entry into the study included freshening within a 3 -wk period and an initial prestudy milk SCC (MSCC) of $<1,500 \times 10^{3}$ cells $/ \mathrm{mL}$ (Fossomatic SCC). Composite milk samples were collected from each ewe every $4 \mathrm{wk}$ for the duration of each ewe's lactation, resulting in a total of 10 sample days for the longest lactating ewes. Composite samples were obtained by hand stripping before attachment of the milking machine after each teat was stripped, dipped, and wiped. Milk samples were subjected to 3 methods of SCC determination: automated FOSS counting, DMSCC with L-W stain, and DMSCC with PMG stain. Individual ewes were dried off when milk production decreased below $0.23 \mathrm{~kg} / \mathrm{d}$. After sampling, milk samples were placed on ice and shipped overnight to the University of Rhode Island. Upon receipt of samples, the milk temperature was recorded and an aliquot of each milk sample was stored at $4^{\circ} \mathrm{C}$ until DMSCC analysis. The remaining milk sample was preserved (Microtabs II, Weber Scientific, Hamilton, NJ) and shipped on ice, overnight, for determination of FOSS SCC (Dairy One Cooperative Inc., Ithaca, NY) and milk component analysis (fat, protein, TS, and MUN).

A single technician who prepared, stained, and read the slides received training on smear preparation and DMSCC staining from the regulatory laboratory of the Rhode Island Department of Health (Providence, RI) and the New York State Department of Agriculture and Markets Food Laboratory (Albany, NY) in methodology associated with L-W and PMG staining and slide reading, respectively. The DMSCC was determined on a prepared smear from each milk sample according to methods from the Department of Health and Human Services' Regulatory Laboratory (Form FDA 2400d). Briefly, samples were agitated by shaking 25 times in $7 \mathrm{~s}$ with a 1 -ft movement, and then $10 \mu \mathrm{L}$ of milk was transferred onto a $1-\mathrm{cm}^{2}$ circle on an Angstadt-Weber milk slide (Weber Scientific, Hamilton, NJ) and distributed over the calibrated area using a dissecting needle with a blunt, bent point. The slide was dried on a $42^{\circ} \mathrm{C}$ heating block. Dried smears were stored overnight and then stained with L-W and PMG stains. Smears were stained by using either the L-W modification of the Newman-Lampert stain (Weber Scientific) for L-W smears or the New York modification of the pyronin Y-methyl green stain (Weber Scientific) for the PMG smears. Briefly, dried smears for L-W staining were dipped in L-W stain for 2 min, dried thoroughly, and rinsed 3 times in $44^{\circ} \mathrm{C}$ distilled water. Dried smears for PMG staining were dipped in Carnoy's fixative for $5 \mathrm{~min}, 50 \%$ ethanol for $1 \mathrm{~min}$, and $30 \%$ ethanol for 1 min. Slides were rinsed in distilled water for $1 \mathrm{~min}$, dipped in the PMG stain for 6 min, and flushed briefly in n-butyl alcohol followed by xylene. Once dry, all slides were stored in a slide box protected from light. Slides were examined under immersion oil, and cells $\geq 4$ $\mu \mathrm{m}$ in diameter possessing a dark blue or dark purple nucleus were counted. Cell fragments were counted if greater than $50 \%$ of their nuclear material was visible. Clusters of cells were counted as one cellular unit unless their nuclear material was clearly separated. Only cells touching either the top or bottom half of the field strips were counted, and a strip count was recorded for each slide. The field diameter was measured with a stage micrometer to calculate the single strip factor (SSF) according to the formula $\mathrm{SSF}=10,000 /(11.28 \times$ diameter). The SSF was multiplied by each strip count to determine DMSCC $/ \mathrm{mL}$. Regulatory procedures obtain DMSCC determinations from single smears. Duplicate milk smears were prepared for each sample and DMSCC was determined on the first of the 2 smears. If the first smear exhibited cracking or peeling, DMSCC was determined on the second of the 2 smears. To confirm the technical consistency of the DMSCC procedure in our laboratory, duplicate L-W and PMG smears were read for 30 samples and the CV was determined (L-W: 4.5\%; PMG: $7.4 \%$ ) and considered acceptable.

The mixed procedure in SAS (SAS System for Windows, Version 9.1, 2003; SAS Institute Inc., Cary, NC) was used to analyze all SCC data. The random effect of sheep was accounted for with a repeated measures approach. The FOSS, L-W, and PMG MSCC were nonnormally distributed. Therefore, a natural logarithm was applied to these data to normalize the variances before the statistical analysis. The appropriate error structure was assessed and applied. Independent variables offered into each model included treatment (SCC determination method), sampling day, and SCC determination method $\times$ sampling day. Variables were removed by backward elimination based on order of least significance. Tukey's adjusted $P$-values were calculated to adjust for multiple 2 -way comparisons. Once the final model was chosen, residuals were checked for homoscedasticity, outliers, leverage cases, and normal distribution. The least squares means and $95 \%$ CI of the 
FOSS, L-W, and PMG MSCC were back-transformed to original units of measure for data presentation. The 95\% CI were used to estimate the standard error in original units of measure and as such are an approximation of the true standard error (Stellflug, 2006). Significance was defined as $P \leq 0.05$.

Milk samples were obtained every 4 wk from November 2007 through July 2008. At the start of the study 42 ewes (20 to 43 DIM) were sampled. One sample spilled during shipment (sampling d 3) and 2 study ewes were missed at milking on sampling day 9. The DIM range and numbers of ewes sampled for the 10 sample days are as follows: Sample d 1 (20 to 43 DIM, $\mathrm{n}=42)$, sample d 2 (47 to 70 DIM, $\mathrm{n}=41$ ), sample d 3 (76 to 99 DIM, n = 39), sample d 4 (104 to 127 DIM, n $=40)$, sample d 5 (132 to 155 DIM, $\mathrm{n}=40)$, sample d 6 (160 to 183 DIM, $\mathrm{n}=26$ ), sample d 7 (188 to 211 DIM, $\mathrm{n}=26)$, sample d 8 (216 to 239 DIM, $\mathrm{n}=16)$, sample d 9 (244 to 267 DIM, n = 14), and sample d $10(272$ to 295 DIM, $\mathrm{n}=16)$. Although a loss of animals occurred over the course of the study as milk production decreased below $0.23 \mathrm{~kg} / \mathrm{d}$, the loss of sheep would not affect treatment differences, as treatment was applied to the sheep milk.

Milk component analyses are presented in Table 1. Least squares means \pm standard errors for FOSS, $\mathrm{L}-\mathrm{W}$, and PMG by sampling day are shown (Figure 1). A treatment (SCC determination method) by time (sampling day) interaction $(P<0.001)$ was observed. The DMSCC from milk smears stained with L-W were greater than from those stained with PMG (sampling d 1, 2, 4, 5, 6, and 9; $P<0.05)$ and analyzed by FOSS (sampling d 2, 3, 4, 5, 6, and 7, $P<0.01$ ) on 6 of the 10 sample days. Although the LSM of L-W was greater than both PMG and FOSS on the other 4 sample days, the magnitude of the differences was not significant. Milk smears stained with PMG did not differ from those analyzed by FOSS at any sampling. The average MSCC for L-W, PMG, and FOSS were $275 \pm 36 \times$ $10^{3}, 174 \pm 24 \times 10^{3}$, and $164 \pm 24 \times 10^{3}$ cells $/ \mathrm{mL}$, respectively. The DMSCC for milk stained with L-W was $58 \%$ greater than milk stained with PMG and $68 \%$ greater than the FOSS analysis. These results are similar to the findings of previous studies in which DNAspecific methods of SCC determination in goat milk, such as FOSS and PMG, did not differ from each other (Dulin et al., 1982; Droke et al., 1993) but DMSCC using the nonspecific L-W stain resulted in an SCC $133 \%$ greater than PMG or $117 \%$ greater than FOSS SCC (Dulin et al., 1982). The difference in magnitude in the elevation of SCC using L-W compared with PMG and FOSS between the current study and Dulin et al. (1982) can be attributed the presence of greater numbers of cytoplasmic particles in goat milk (Dulin et al., 1983; Droke et al., 1993; Sanchez et al., 2005). A more recent study evaluated the effect of analytical conditions on FOSS SCC and DMSCC using methylene blue and PMG stains on multiple aliquots of single milk samples obtained from 80 ewes (Gonzalo et al., 2003). No difference was found between FOSS SCC analysis and either of the DMSCC stains, and the DMSCC stains did not differ from each other when considering the samples assayed under analytical conditions most similar to the current study. Although DMSCC using the PMG stain was found to be slightly more repeatable than that using methylene blue (Gonzalo et al., 2003), based upon the residual standard deviation, this difference was not significant. Direct comparison of the Gonzalo et al. (2003) study with the current study is difficult because the methylene blue and PMG staining procedures differed from the FDA regulatory DMSCC procedures (Fitts and Laird, 2004). Additionally, the Gonzalo et al. (2003) study was based on the repeated analysis of a single sample from 80 ewes versus the current study in which a total of 300 milk samples were obtained from 42 ewes sampled up to 10 times over the length of their lactation. The primary procedural difference between the Gonzalo et al. (2003) procedures and FDA regulatory procedure is the length of time smears are immersed in staining solutions. In the Gonzalo et al. (2003) study, the smears were stained in methylene blue for 30 min and PMG for 20 min versus 2 min and 6 min, respectively, in the current study. In addition, the temperature of the water used for rinsing the methylene blue slides after staining is 35 to $45^{\circ} \mathrm{C}$ for FDA regulatory procedures versus ambient temperature in the Gonzalo et al. (2003) study. Although the cumulative effect of these procedural differences is unknown, it is speculated that the increase in staining time and different wash procedure used by Gonzalo et al. (2003) could decrease contrast and subsequently mask cells that might otherwise be counted. Moreover, the diameter of the somatic cells counted in the Gonzalo et al. (2003) study was not specified and could have differed from FDA regulatory DMSCC procedures.

When the effect of sampling day within staining method was analyzed, no difference was observed over sampling day for FOSS and DMSCC with L-W stain. An effect of sampling day on DMSCC was observed using PMG stain, with DMSCC on sampling d 7 (188 to 211 DIM) being greater than DMSCC on sample d 8 (216 to 239 DIM, $P<0.001)$ and sample d 9 (244 to 267 DIM, $P<0.01$ ); the biologic significance of this finding is unknown. Previous research has demonstrated that SCC gradually increases with stage of lactation in cows (Paape et al., 2007) and goats (Dulin et al., 1983; Gomes et al., 2006; Paape et al., 2007) but not in sheep (Paape et al., 2007). The current study findings suggest 
Table 1. Average milk component analysis of dairy ewes over lactation ${ }^{1}$

\begin{tabular}{|c|c|c|c|c|c|c|}
\hline $\begin{array}{l}\text { Sampling } \\
\text { day }\end{array}$ & DIM & $\begin{array}{c}\mathrm{SCC}^{2} \\
\left(\times 10^{3} \text { cells } / \mathrm{mL}\right)\end{array}$ & $\begin{array}{c}\text { True } \\
\text { protein }(\%)\end{array}$ & $\begin{array}{l}\text { Fat } \\
(\%)\end{array}$ & $\begin{array}{c}\text { MUN } \\
(\mathrm{mg} / \mathrm{dL})\end{array}$ & $\begin{array}{l}\mathrm{TS}^{3} \\
(\%)\end{array}$ \\
\hline 1 & $20-43$ & $207 \pm 57$ & $4.96 \pm 0.08$ & $9.29 \pm 0.41$ & $26.44 \pm 0.97$ & $19.95 \pm 0.38$ \\
\hline 2 & $47-70$ & $120 \pm 34$ & $5.07 \pm 0.07$ & $8.61 \pm 0.43$ & $29.99 \pm 0.72$ & $19.56 \pm 0.40$ \\
\hline 4 & $104-127$ & $160 \pm 45$ & $5.20 \pm 0.07$ & $7.40 \pm 0.36$ & $29.01 \pm 0.78$ & $18.44 \pm 0.36$ \\
\hline 5 & $132-155$ & $172 \pm 48$ & $5.12 \pm 0.09$ & $8.51 \pm 0.30$ & $12.37 \pm 0.62$ & $19.20 \pm 0.29$ \\
\hline 6 & $160-183$ & $206 \pm 70$ & $5.22 \pm 0.11$ & $8.95 \pm 0.55$ & $35.95 \pm 1.78$ & $19.95 \pm 0.56$ \\
\hline 10 & $272-295$ & $105 \pm 43$ & $4.41 \pm 0.09$ & $6.77 \pm 0.53$ & $15.06 \pm 0.94$ & - \\
\hline
\end{tabular}

${ }^{1}$ Mean \pm standard error except where noted. Analysis performed by Dairy One Inc. (Ithaca, NY).

${ }^{2}$ Fossomatic (Foss, Hillerød, Denmark) analysis conducted by Dairy One Inc. Values are least squares means \pm SE. Least squares means and confidence intervals of the milk SCC were changed back to their original units after analysis.

${ }^{3}$ Missing data from sample d 10 .

a decrease in SCC with advanced DIM; however, from sampling d 8 to 10 the sample size was less than half of the initial number and thus it is possible that the sheep with greater SCC did not complete the full length of the study up to sampling d 10.

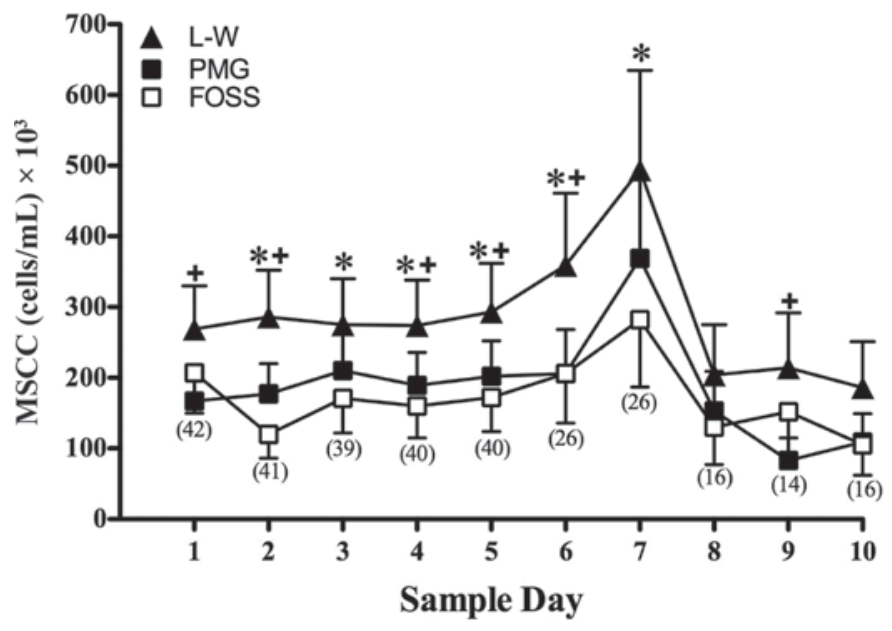

Figure 1. Comparison of staining procedures for determination of SCC in sheep milk. Milk samples from commercial, East Friesian purebred and crossbred dairy ewes (n) were used in this study. Composite milk samples were collected every 4 wk throughout lactation. The DIM ranges for the sample days were as follows: sample d 1 (20 to 43 DIM), sample d 2 (47 to 70 DIM), sample d 3 (76 to 99 DIM), sample d 4 (104 to 127 DIM), sample d 5 (132 to 155 DIM), sample d 6 (160 to 183 DIM), sample d 7 (188 to 211 DIM), sample d 8 (216 to 239 DIM), sample d 9 (244 to 267 DIM), and sample d 10 (272 to 295 DIM). Variables were log-transformed and analyzed. Values are least squares means \pm SE. Least squares means and confidence intervals of the milk SCC were changed back to their original units after analysis. An approximate SE for original units was estimated utilizing the $95 \%$ CI. The milk SCC (MSCC) of smears stained with Levowitz-Weber (L-W) were greater than those stained with pyronin Y-methyl green $(\mathrm{PMG},+, P<0.05)$ or analyzed by Fossomatic (FOSS, $\left.{ }^{*}, P<0.01\right)$ in 6 of the 10 mo sampled.
In conclusion, DMSCC of sheep milk stained with the nonspecific, methylene blue L-W stain resulted in a marked increase in SCC over that of DNA-specific stains PMG and the ethidium bromide dye used in FOSS SCC analysis. The findings of this study support the continued use of FOSS SCC but recommend the replacement of the methylene blue-based stains with DNA-specific PMG for determination of DMSCC in sheep milk.

\section{ACKNOWLEDGMENTS}

The authors thank Lynn Hinckley, National Conference on Interstate Milk Shipments, Other Species Milk Committee Chairperson (University of Connecticut, Storrs), for her guidance and support during all phases of this project. We also thank Tom Clark (Old Chatham Sheepherding Company, Old Chatham, NY), Daniel Rice and Cynthia Mangione (New York State Department of Agriculture and Markets Food Laboratory, Albany, NY), and Kerry Patterson (Rhode Island Department of Health, Providence) for the generous donation of their time and resources and students Emily Mirek and Stacey O'Donnell (University of Rhode Island, Kingston) for their pioneering spirit. Funding for this study was provided by the College of the Environment and Life Sciences, University of Rhode Island and CSREES RIAES RH00129.

\section{REFERENCES}

Droke, E. A., M. J. Paape, and A. L. Di Carlo. 1993. Prevalence of high somatic cell counts in bulk tank goat milk. J. Dairy Sci. 76:1035-1039.

Dulin. A. M., M. J. Paape, W. D. Schultze, and B. T. Weinland. 1983. Effect of parity, stage of lactation, and intramammary infection on concentration of somatic cells and cytoplasmic particles in goat milk. J. Dairy Sci. 66:2426-2433.

Dulin, A. M., M. J. Paape, and W. P. Wergin. 1982. Differentiation and enumeration of somatic cells in goat milk. J. Food Prot. 45:435-439. 
Fitts, J. E., and D. Laird. 2004. Direct microscopic methods for bacteria or somatic cells. in Standard Methods for the Examination of Dairy Products. 17th ed. H. M. Wehr and J. F. Frank, ed. American Public Health Association, Washington, DC.

Gomes, V., A. M. M. P. D. Libera, M. Paiva, K. M. Madureira, and W. P. Araújo. 2006. Effect of stage of lactation on somatic cell counts in healthy goats (Caprae hircus) breed in Brazil. Small Rumin. Res. 6:30-34.

Gonzalo, C., J. R. Martinez, J. A. Carrledo, and F. San Primitivo. 2003. Fossomatic cell-counting on ewe milk: Comparison with direct microscopy and study of variation factors. J. Dairy Sci. $86: 138-145$.

Marth, E. H. 1978. Standard Methods for the Examination of Dairy Products. 14th ed. American Public Health Association, Washington, DC.

Martinez, J. R., C. Gonzalo, and F. San Primitivo. 1997. Valoración de méto-dos de recuento celular en leche de oveja. ITEA Tomo II 18:570-572.
Paape, M., G. R. Wiggans, D. D. Bannerman, D. L. Thomas, A. H. Sanders, A. Contreras, P. Moroni, and R. H. Miller. 2007. Monitoring goat and sheep millk somatic cell counts. Small Rumin. Res. 68:114-125.

PMO. 2007. Grade "A" Pasteurized Milk Ordinance (PMO). United States Department of Health and Human Services, Washington, DC.

Sánchez, A., D. Sierra, C. Luengo, J. C. Corrales, C. T. Morales, A. Contreras, and C. Gonzalo. 2005. Influence of storage and preservation on Fossomatic cell count and composition of goat milk. J. Dairy Sci. 88:3095-3100.

Stellflug, J. N. 2006. Comparison of cortisol, luteinizing hormone, and testosterone responses to a defined stressor in sexually inactive rams and sexually active female-oriented and male-oriented rams. J. Anim. Sci. 84:1520-1525. 